\title{
Effects of exenatide on postprandial vascular endothelial dysfunction in type 2 diabetes mellitus
}

Keiichi Torimoto, Yosuke Okada, Hiroko Mori, Takashi Otsuka, Mayuko Kawaguchi, Megumi Matsuda, Fumi Kuno, Kei Sugai, Satomi Sonoda, Maiko Hajime, Kenichi Tanaka, Tadashi Arao and Yoshiya Tanaka*

\begin{abstract}
Background: Basic studies have shown that glucagon-like peptide-1 (GLP-1) analogs exert a direct protective effect on the vascular endothelium in addition to their indirect effects on postprandial glucose and lipid metabolism. GLP-1 analogs are also reported to inhibit postprandial vascular endothelial dysfunction. This study examined whether the GLP-1 analog exenatide inhibits postprandial vascular endothelial dysfunction in patients with type 2 diabetes mellitus (T2DM).

Methods: Seventeen patients with T2DM underwent a meal tolerance test to examine changes in postprandial vascular endothelial function and in glucose and lipid metabolism, both without exenatide (baseline) and after a single subcutaneous injection of $10 \mu \mathrm{g}$ exenatide. Vascular endothelial function was determined using reactive hyperemia index $(\mathrm{RHI})$ measured by peripheral arterial tonometry before and 120 min after the meal loading test. The primary endpoint was the difference in changes in postprandial vascular endothelial function between the baseline and exenatide tests.
\end{abstract}

Results: The natural logarithmically-scaled RHI (L_RHI) was significantly lower after the baseline meal test but not in the exenatide test. The use of exenatide resulted in a significant decrease in triglycerides (TG) area under the curve and coefficient of variation (CV). The change in L_RHI correlated with changes in CV of triglycerides and HDL-cholesterol. Multivariate analysis identified changes in triglyceride $\mathrm{CV}$ as the only determinant of changes in $\mathrm{L} R \mathrm{RH}$, contributing to $41 \%$ of the observed change.

Conclusions: Exenatide inhibited postprandial vascular endothelial dysfunction after the meal loading test, suggesting that exenatide has a multiphasic anti-atherogenic action involving not only glucose but also lipid metabolism.

Trial registration: ClinicalTrials.gov: UMIN000015699.

Keywords: Exenatide, Reactive hyperemia index (RHI), T2DM, Endothelium function

\section{Background}

Patients with type 2 diabetes mellitus (T2DM) are at high risk for development of life-threatening atherosclerotic disease compared with healthy persons. For example, the risk of coronary artery disease is 2.0 times higher, and the risk of cerebral infarction is 2.3 times higher in these patients [1]. It is presumed that vascular endothelial dysfunction precedes clinically-evident diabetic macrovasculopathy [2] and that the former is due to various factors such as abnormal glucose and lipid

\footnotetext{
* Correspondence: tanaka@med.uoeh-u.ac.jp

First Department of Internal Medicine, School of Medicine, University of Occupational and Environmental Health, 1-1 Iseigaoka, Yahatanishi-ku,
} Kitakyushu-shi 807-8555, Japan metabolism, inflammation, hypertension, obesity, sedentary life style, smoking, high salt intake, and menopause [3]. Among these factors, it seems that postprandial changes in glucose and lipid metabolism are particularly important risk factors for vascular endothelial dysfunction [4].

Both clinical and experimental evidences suggest that oxidative stress and hypercytokinemia are associated with postprandial hyperglycemia [5] and that postprandial hyperlipidemia enhances the progression of atherosclerosis in patients with T2DM [6]. Therefore, correction of postprandial metabolic disorders and inhibition of vasculopathy through the above pathways could potentially prevent the progression of atherosclerosis.

\section{Ciomed Central}

(c) 2015 Torimoto et al.; licensee BioMed Central. This is an Open Access article distributed under the terms of the Creative Commons Attribution License (http://creativecommons.org/licenses/by/4.0), which permits unrestricted use, distribution, and reproduction in any medium, provided the original work is properly credited. The Creative Commons Public Domain Dedication waiver (http://creativecommons.org/publicdomain/zero/1.0/) applies to the data made available in this article, unless otherwise stated. 
Previous studies reported that incretin analogs do not only indirectly correct postprandial glucose and lipid metabolism [7], but they also inhibit vascular endothelial dysfunction by their direct protective effects on the vascular endothelium, such as enhancement of nitric oxide (NO) production [8] and anti-inflammatory action [9]. In actual clinical settings, long-term administration of sitagliptin is reported to improve vascular endothelial function [10] and exert anti-arteriosclerosis action [11]. Clinically, glucagon-like peptide-1 (GLP-1) receptor agonists are known to improve pro-atherosclerosis factors, such as glucose metabolism, lipid metabolism, blood pressure, and body weight and that their long-term effects include improvement of vascular endothelial function. In addition, one study reported that continuous intravenous infusion of GLP-1 resulted in short-term, blood glucose-independent improvement of vascular endothelial dysfunction [12]. To our knowledge, only a few studies have verified the effects of GLP-1 receptor agonists on postprandial vascular endothelial dysfunction in daily clinical practice, and only little is known at present on the mechanism of the inhibitory effects of these drugs on vascular endothelial dysfunction. The present study examined the effects of exenatide, a GLP-1 receptor agonist, on postprandial vascular endothelial dysfunction after meal loading test in Japanese patients with T2DM.

\section{Methods}

\section{Study subjects}

This study included 17 patients with T2DM who were admitted to the University of Occupational and Environmental Health Hospital (UOEH) or Wakamatsu Hospital of UOEH between June 2011 and February 2014 and who met the following inclusion criteria: 1) age 20 to less than 80 years; 2) no change in treatment with oral glucose-lowering agents, lipid-lowering agents, and anti-hypertensive agents during the 12 weeks preceding enrollment; and 3) ongoing treatment by diet regimen alone or by therapy with sulfonylurea, sulfonylurea plus biguanide, or sulfonylurea plus thiazolidine derivatives. Patients who met any of the following criteria were excluded from the study: 1) treatment of diabetes with insulin; 2) experience of episodes of diabetic ketoacidosis, nonketotic hyperosmolar coma, infection, or acute coronary syndrome; 3) pregnancy or possible pregnancy; 4) history of stroke or ischemic heart disease within the preceding 6 months; 5) history of pancreatitis; and 6) cardiac arrhythmia.

This study was approved by the ethics committee of the UOEH, and the subjects received written information about the study and gave consent to participate in the study.

\section{Study design}

All 17 patients with T2DM were admitted to the hospital and underwent meal tolerance test to examine changes in postprandial endothelial function and changes in glucose and lipid metabolism (day 1). The test was repeated the next day $15 \mathrm{~min}$ after subcutaneous injection of $10 \mu \mathrm{g}$ exenatide (Byetta ${ }^{\circ}$; AstraZeneca K.K., Osaka, Japan) (day 2). Both tests were carried out early in the morning after $12 \mathrm{~h}$ of fasting. With regard to the meal tolerance test, a test meal (total $450 \mathrm{kcal} ; 51.4 \%$ carbohydrate, $33.3 \%$ fat, and $15.3 \%$ protein, a recipe proposed by a working group of the Japan Diabetes Society) [13] was used, and blood was analyzed before and 30, 60, 120, and 240 min after meal loading to evaluate changes in glucose and lipid metabolism. In addition, vascular endothelial function was evaluated before and $120 \mathrm{~min}$ after meal loading, using a peripheral arterial tonometry (PAT) device (EndoPAT2000; Itamar Medical, Caesarea, Israel). The evaluation items related to glucose metabolism included plasma glucose and plasma immunoreactive insulin (IRI). The evaluation items related to lipid metabolism were triglycerides, high-density lipoprotein cholesterol (HDL-C), and low-density lipoprotein cholesterol (LDL-C). The area under the curve (AUC) and the coefficient of variation $(\mathrm{CV})$ were calculated for plasma glucose and IRI based on data obtained at 5 measurement points from 0 to $240 \mathrm{~min}$. The primary endpoint was changes in vascular endothelial function at 0 and $120 \mathrm{~min}$ after meal loading test conducted after exenatide, relative to the control (test without exenatide).

\section{Noninvasive vascular function test}

The PAT-based method used for digital assessment of vascular function has been described in detail previously [14]. After an acclimatization period $30 \mathrm{~min}$ in a room controlled for temperature and light in the fasting state, the baseline pulse amplitude was recorded during a period of $5 \mathrm{~min}$ before the induction of ischemia. The latter was induced by placing the sphygmomanometer cuff on the upper arm, while the opposite arm served as a control. The PAT probes were placed on one finger of each hand. After $5 \mathrm{~min}$, the blood pressure cuff was inflated to $60 \mathrm{mmHg}$ above the systolic pressure or $200 \mathrm{mmHg}$ for $5 \mathrm{~min}$ and then deflated to induce reactive hyperemia. As a measure of reactive hyperemia, the reactive hyperemia index (RHI) was calculated as the ratio of the average amplitude of the PAT signal over $1 \mathrm{~min}$ beginning $1.5 \mathrm{~min}$ after cuff deflation (control arm, A; occluded arm, C) divided by the average amplitude of the PAT signal over the 2.5-min time period before cuff inflation (baseline) (control arm, B; occluded arm, D). Thus, $\mathrm{RHI}=(\mathrm{C} / \mathrm{D}) /(\mathrm{A} / \mathrm{B}) \times$ baseline correction . Because RHI has a heteroscedastic error structure, we used natural logarithm transformation in all analyses. 


\section{Measurement of blood HbA1c, plasma glucose, IRI and serum lipids}

Blood samples were collected early in the morning after at least 12 -h fasting, through a venous line placed in the median vein using an indwelling catheter. Plasma lipid was measured with a Hitachi 7350 autoanalyzer (Hitachi Co., Tokyo, Japan). HDL-C, and triglycerides levels were determined by using an enzymatic method, and both enzymatic method and direct technique were used for LDL-C. The insulin resistance index (homeostasis model assessment of insulin resistance) was calculated according to the formula: fasting IRI $(\mathrm{mU} / \mathrm{L}) \times$ fasting glucose $(\mathrm{mg} / \mathrm{dL}) / 405$. Hemoglobin Alc (HbA1c) was measured by high-pressure liquid chromatography using the Tosoh HLC-723 G8 (Tosoh Co., Kyoto, Japan). The HbAlc level was obtained as a national glycohemoglobin standardization program value by adding $0.4 \%$ to the value expressed as the conventional Japanese standard substance value [15].

\section{Statistical analysis}

Values are expressed as mean \pm standard error. Hypoglycemia, requiring glucose intake, developed in two patients during the meal tolerance test after exenatide administration. Excluding these two patients, the analysis included 15 patients. Wilcoxon's signed rank test was used to compare natural logarithmic-scaled RHI (L_RHI) values at 0 or $120 \mathrm{~min}$ after the baseline and exenatide meal loading tests. The Friedman test was used to compare various parameters at $0,30,60,120$, and $240 \mathrm{~min}$ after meal loading. Spearman's correlation method was used for analysis of the correlation between L_RHI and changes in glucose metabolism or lipid metabolism. Multivariate analysis used the difference between changes in L_RHI in the baseline and exenatide meal tolerance tests as the dependent variable. The independent variables were age, sex, body mass index (BMI), disease duration, and differences between changes in blood glucose AUC, changes in triglycerides $\mathrm{CV}$, and changes in HDL-C CV without exenatide compared with exenatide administration. The step-up procedure was used for this analysis. Statistical analyses were conducted using SPSS Statistical Software version 19.0 (SPSS Inc., Chicago, IL), and the results were regarded as significant when the $p$ value was $<0.05$.

\section{Results}

\section{Clinical characteristics}

Table 1 shows the patient characteristics. Since the administration of exenatide resulted in hypoglycemia in two patients during the meal tolerance test, they were excluded from the study. Thus, the study subjects were 15 patients with T2DM. The subjects were 15 patients (13 men and 2 women) with a mean age of $53.2 \pm 2.6$
Table 1 Baseline characteristics

\begin{tabular}{|c|c|}
\hline Age (years) & $53.2 \pm 2.6$ \\
\hline Gender (male/female) & $13 / 2$ \\
\hline Body mass index $\left(\mathrm{kg} / \mathrm{m}^{2}\right)$ & $27.1 \pm 1.5$ \\
\hline Duration of diabetes (years) & $7.0 \pm 1.0$ \\
\hline \multicolumn{2}{|l|}{ Diabetes complication } \\
\hline Neuropathy & $9(60.0)$ \\
\hline Retinopathy & $2(13.3)$ \\
\hline Nephropathy & $0(0.0)$ \\
\hline \multicolumn{2}{|l|}{ Diabetes therapy } \\
\hline Diet only & $2(13.3)$ \\
\hline Sulfonylurea & $12(80.0)$ \\
\hline Pioglitazone & $0(0.0)$ \\
\hline Metformin & $3(20.0)$ \\
\hline \multicolumn{2}{|l|}{ Other treatments } \\
\hline Lipid-lowering drugs & $4(26.7)$ \\
\hline Antihypertensive drugs & $5(48.8)$ \\
\hline Current smokers & $9(60.0)$ \\
\hline Cardiovascular disease & $2(13.3)$ \\
\hline Systolic blood pressure (mmHg) & $127.4 \pm 4.3$ \\
\hline Diastolic blood pressure $(\mathrm{mmHg})$ & $80.6 \pm 3.3$ \\
\hline LDL-C (mg/dL) & $119.5 \pm 9.3$ \\
\hline $\mathrm{HDL}-\mathrm{C}(\mathrm{mg} / \mathrm{dL})$ & $45.7 \pm 3.5$ \\
\hline Triglycerides (mg/dL) & $153.0 \pm 9.5$ \\
\hline $\mathrm{HbA1c}(\%)$ & $9.5 \pm 0.4$ \\
\hline Fasting plasma glucose (mg/dL) & $153.0 \pm 9.5$ \\
\hline Immunoreactive insulin $(\mu \mathrm{U} / \mathrm{mL})$ & $7.4 \pm 1.1$ \\
\hline HOMA-IR & $2.8 \pm 0.5$ \\
\hline HOMA- $\beta$ & $32.2 \pm 5.7$ \\
\hline C-peptide in urine ( $\mu \mathrm{g} /$ day) & $101.2 \pm 18.8$ \\
\hline L_RHI & $0.54 \pm 0.04$ \\
\hline
\end{tabular}

Data are mean $\pm S E, n$, or $n(\%) . n=15$.

Abbreviations: $L D L-C$ low-density lipoprotein cholesterol, $H D L-C$ high-density lipoprotein cholesterol, TG triglycerides, HbA1c hemoglobin A1c, HOMA-IR homeostasis model assessment as an index of insulin resistance, HOMA- $\beta$ homeostasis model assessment beta cell function, $L_{-} R H I$ the natural logarithmic scaled reactive hyperemia index.

(range, 35-71) years. They were mildly obese, with a mean BMI of $27.1 \pm 1.5 \mathrm{~kg} / \mathrm{m}^{2}$. The mean duration of diabetes mellitus was $7.0 \pm 1.0$ (range, 1-14) years. The mean fasting plasma glucose was $153.0 \pm 9.5$ (range, 114-270) $\mathrm{mg} / \mathrm{dL}, \mathrm{HbA} 1 \mathrm{c}$ was $9.5 \pm 0.4 \%$ (range, 7.6$13.7 \%$ ), and the insulin level was $7.4 \pm 1.1$ (range, 2.2-16.2) $\mu \mathrm{U} / \mathrm{mL}$. LDL-C was $119.5 \pm 9.3$ (range, 64-202) $\mathrm{mg} / \mathrm{dL}$, $\mathrm{HDL}-\mathrm{C}$ was $45.7 \pm 3.5$ (range, 29-86) $\mathrm{mg} / \mathrm{dL}$, and triglycerides was $153.0 \pm 9.5$ (range, 105-286) $\mathrm{mg} / \mathrm{dL}$.

Thirteen of the 15 patients were on oral hypoglycemic drugs: 1 on metformin monotherapy, 2 on metformin plus sulfonylurea, and 10 on sulfonylurea monotherapy. 
Two patients (13.3\%) had history of cardiovascular diseases, and $4(26.7 \%)$ were on lipid-lowering agents.

The L_RHI was $0.54 \pm 0.04$ (range, 0.23-1.03), and there was no significant sex-related difference in L_RHI.

\section{Postprandial changes in glucose metabolism and lipid profile after meal tolerance test}

Glucose metabolism dynamics and lipid metabolism profile are shown in Figure 1 and Table 2. The baseline meal tolerance test was followed by significant increases in plasma glucose, IRI, and triglycerides ( $\mathrm{p}<0.001$, each), with peak values registered at $2 \mathrm{~h}$ (Figure 1 ). Furthermore, the test was followed by significant decreases in LDL-C and HDL-C ( $<<0.001$, each), with a trough occurring at $2 \mathrm{~h}$ after meal.

On the other hand, the exenatide meal tolerance test was followed by a significant decrease in plasma glucose, with a trough at $2 \mathrm{~h}$ after the test $(\mathrm{p}<0.001)$. Furthermore, no postprandial increase was noted in triglycerides, and the triglycerides values were significantly lower at 60,120 , and $240 \mathrm{~min}$ after the meal compared with the corresponding values after the baseline test $(\mathrm{p}<$ 0.001 , each).

Table 2 compares the results of the two tests. Although plasma glucose AUC was significantly lower after the exenatide test than baseline meal load test (855 vs. $442 \mathrm{mg} / \mathrm{dL} \cdot \mathrm{h}, \mathrm{p}=0.001$ ), the IRI AUC was not different (97 vs. $85 \mu \mathrm{U} / \mathrm{mL} \cdot \mathrm{h}, \mathrm{p}=0.211$ ). The exenatide meal test resulted in significant improvement in triglycerides AUC (617 vs. $476 \mathrm{mg} / \mathrm{dL} \cdot \mathrm{h}, \mathrm{p}=0.001$ ) and triglycerides $\mathrm{CV}$ (0.15 vs. $0.06, \mathrm{p}=0.001)$.

\section{Postprandial changes in endothelial function after meal tolerance test}

Figure 2 shows changes in L_RHI after the test meal. L_RHI was significantly lower after the baseline test meal, compared with the value before the test ( 0.46 vs $0.54, \mathrm{p}=0.029$ ). In comparison, exenatide prevented the fall in $L_{-}$RHI after the meal test $(0.58$ vs $0.56, \mathrm{p}=0.699)$. In addition, there was no change in pre-meal RHI without exenatide or with a single exenatide injection of $10 \mu \mathrm{g}(0.54$ vs. $0.56 ; \mathrm{P}=0.498)$. However, post-meal RHI increased significantly after a single injection of $10 \mu \mathrm{g}$

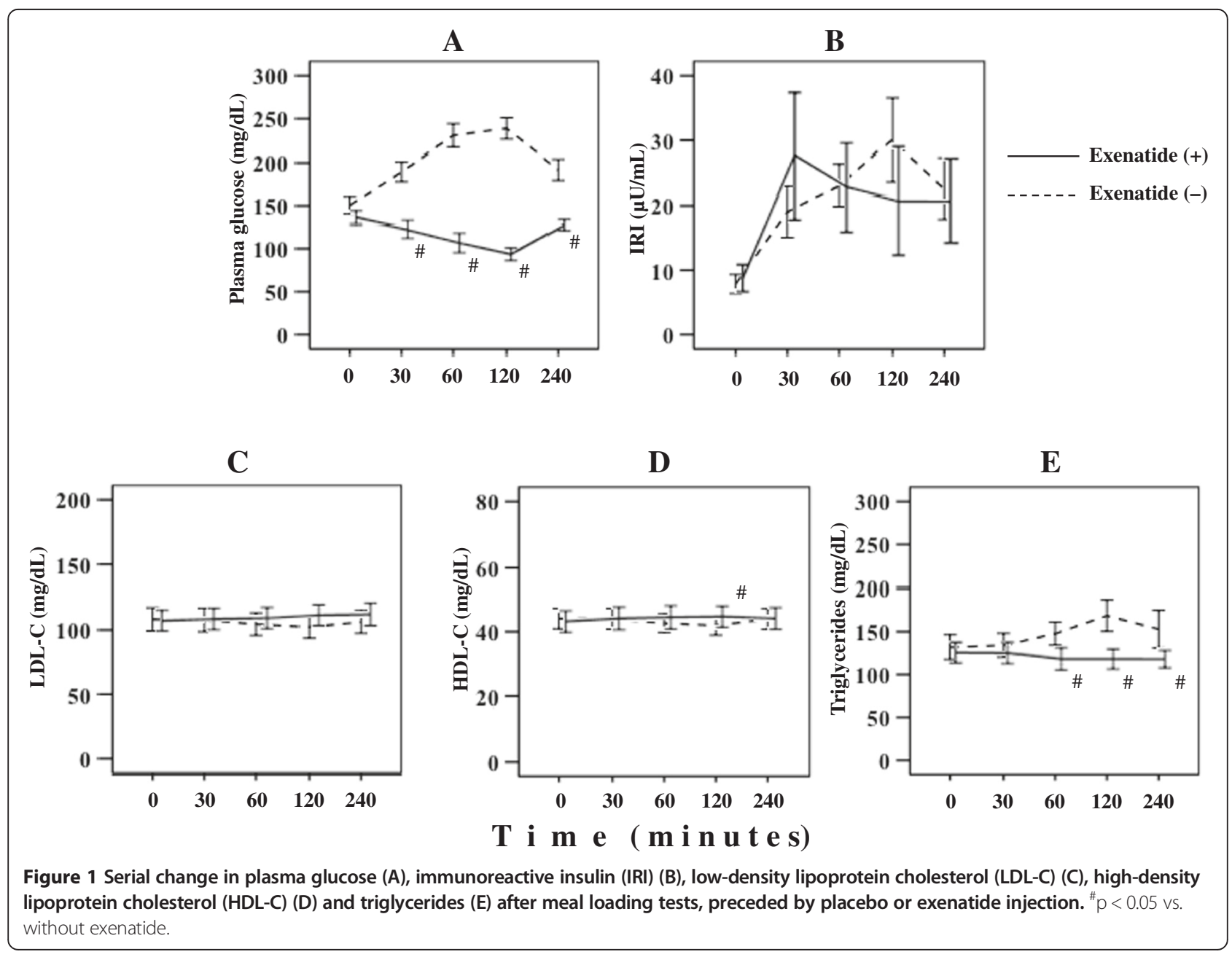


Table 2 Change in glucose and lipid metabolism after meal loading tests, preceded by placebo (baseline) or exenatide injection

\begin{tabular}{|c|c|c|c|}
\hline & Baseline & Exenatide & $P$ value \\
\hline \multicolumn{4}{|l|}{ Glucose metabolism variables } \\
\hline AUC of plasma glucose $[(\mathrm{mg} / \mathrm{dL}) \cdot \mathrm{hr}]$ & $855.4 \pm 45.3$ & $442.3 \pm 26.4$ & 0.001 \\
\hline CV of plasma glucose & $0.19 \pm 0.02$ & $0.20 \pm 0.01$ & 0.776 \\
\hline AUC of IRI $[(\mu \mid \mathrm{U} / \mathrm{mL}) \cdot \mathrm{hr}]$ & $96.7 \pm 18.5$ & $84.6 \pm 28.9$ & 0.211 \\
\hline CV of IRI & $0.49 \pm 0.04$ & $0.53 \pm 0.05$ & 0.427 \\
\hline \multicolumn{4}{|l|}{ Lipid metabolism variables } \\
\hline AUC of TG $[(\mathrm{mg} / \mathrm{dL}) \cdot \mathrm{hr}]$ & $616.8 \pm 68.7$ & $475.5 \pm 45.7$ & 0.001 \\
\hline CV of TG & $0.14 \pm 0.02$ & $0.06 \pm 0.02$ & 0.001 \\
\hline AUC of HDL-C [(mg/dL) $\cdot \mathrm{hr}]$ & $171.8 \pm 12.2$ & $177.2 \pm 13.4$ & 0.064 \\
\hline CV of HDL-C & $0.03 \pm 0.003$ & $0.03 \pm 0.003$ & 0.730 \\
\hline AUC of LDL-C [(mg/dL) $\cdot \mathrm{hr}]$ & $419.0 \pm 35.1$ & $436.3 \pm 32.8$ & 0.221 \\
\hline$C V$ of $L D L-C$ & $0.03 \pm 0.003$ & $0.03 \pm 0.003$ & 0.875 \\
\hline
\end{tabular}

Data are mean \pm SEM.

Abbreviations: AUC area under the curve, $C V$ coefficient of variation, $I R I$ immunoreactive insulin, $T G$ triglycerides, $H D L-C$ high-density lipoprotein cholesterol, $L D L-C$ low-density lipoprotein cholesterol.

exenatide, compared with no exenatide injection (0.46 vs. $0.58 ; \mathrm{P}=0.020$ ). Further analysis showed that the changes in L_RHI after the baseline meal loading test did not correlate with plasma glucose AUC $(r=-0.475, p=0.074)$ or IRI AUC $(r=0.093$, $\mathrm{p}=0.742)$, but correlated with triglycerides $\mathrm{CV}(\mathrm{r}=-0.780$, $\mathrm{p}=0.001$ ).

Table 3 shows the relationship between changes in L_RHI on the exenatide meal tolerance test and changes

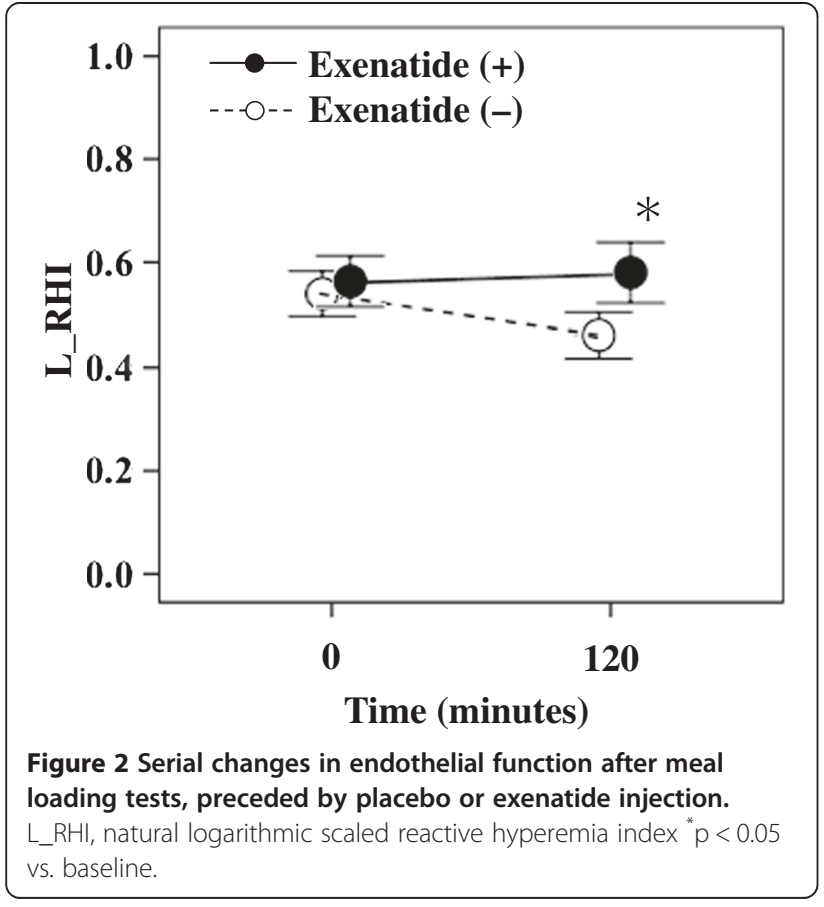

in glucose and lipid metabolism. First, changes in L_RHI correlated with changes in triglycerides CV $(r=-0.727$, $\mathrm{p}=0.003$ ) and changes in HDL-C CV. Second, multivariate analysis was performed using changes in L_RHI on the baseline and exenatide meal tolerance tests as the dependent variable, and age, sex, BMI, disease duration, and changes in blood glucose AUC, triglycerides $\mathrm{CV}$, and HDL-C CV on the same tests as the independent variables. The results identified changes in triglycerides $\mathrm{CV}$ on the two tests as the most significant contributor (contribution ratio, 41\%) to the changes in L_RHI (Table 4).

\section{Discussion}

The present study indicated that single-dose exenatide can inhibit postprandial endothelial dysfunction in Japanese patients with T2DM. Furthermore, a single dose of exenatide corrected abnormalities in postprandial lipid metabolism, with particular improvement in postprandial hypertriglyceridemia, which could explain the observed improvement in postprandial vascular endothelial function. In fact, previous retrospective studies reported that exenatide inhibited the onset of cardiovascular events in patients with T2DM [16] and that liraglutide, another GLP-1 analog, improved intima-media thickening of the carotid artery [17]. These results suggest anti-atherosclerotic activity for members of the GLP-1 family, in addition to their effects on vascular endothelial function.

T2DM is known to be associated with impairment of vascular endothelial function [1], which plays a major role in atherosclerogenesis. Previous studies demonstrated that even one meal can impair vascular endothelial function in patients with T2DM $[4,18]$. This acute vascular endothelial dysfunction is presumed to occur 
Table 3 Correlation coefficients between dL_RHI and clinical markers of glycemia and various nonglycemic metabolic variables

\begin{tabular}{|c|c|c|c|c|c|c|c|c|c|c|}
\hline & dAUC $_{\text {glucose }}$ & $\mathrm{dAUC}_{\mathrm{IRI}}$ & $\mathrm{dAUC}_{\mathrm{TG}}$ & dAUC $_{\mathrm{HDL}}$ & $\mathrm{dAUC}_{\mathrm{LDL}}$ & $\mathrm{dCV}_{\text {glucose }}$ & $\mathrm{dCV}_{\mathrm{IRI}}$ & $\mathrm{dCVTG}_{\mathrm{TG}}$ & $\mathrm{dCV}_{\mathrm{HDL}}$ & $\mathrm{dCV}_{\mathrm{LDL}}$ \\
\hline$d A \cup C_{|R|}$ & -0.39 & & & & & & & & & \\
\hline $\mathrm{dAUC} \mathrm{C}_{\mathrm{TG}}$ & -0.02 & 0.17 & & & & & & & & \\
\hline $\mathrm{dAUC} \mathrm{C}_{\mathrm{HDL}}$ & 0.40 & 0.33 & -.0 .06 & & & & & & & \\
\hline $\mathrm{dAU} \mathrm{C}_{\mathrm{LDL}}$ & -0.10 & $0.60^{*}$ & 0.04 & 0.35 & & & & & & \\
\hline $\mathrm{dCV}_{\text {glucose }}$ & 0.06 & 0.39 & -0.24 & -0.12 & 0.50 & & & & & \\
\hline$d C V_{|R|}$ & -0.43 & $0.58^{*}$ & 0.29 & 0.02 & 0.37 & 0.35 & & & & \\
\hline $\mathrm{dCV}_{\mathrm{TG}}$ & 0.39 & 0.09 & -0.06 & -0.13 & 0.27 & 0.37 & 0.14 & & & \\
\hline $\mathrm{dCV}_{\mathrm{HDL}}$ & 0.44 & -0.26 & -0.23 & -0.46 & -0.09 & -0.30 & 0.01 & $0.64^{*}$ & & \\
\hline $\mathrm{dCV}_{\mathrm{LDL}}$ & 0.35 & 0.35 & -0.22 & -0.42 & -0.24 & -0.24 & $-0.60^{*}$ & 0.14 & 0.38 & \\
\hline $\mathrm{dL} \_\mathrm{RHI}$ & -0.37 & 0.33 & 0.24 & 0.16 & -0.17 & -0.19 & 0.29 & $-0.73^{* *}$ & $-0.61^{*}$ & -0.33 \\
\hline
\end{tabular}

Data are results of Spearman rank correlation. ${ }^{*} \mathrm{P}<0.05,{ }^{*} \mathrm{P}<0.01$.

Abbreviations: $d A U C$ change in the area under the curve, IRI Immunoreactive insulin, $L D L$ low-density lipoprotein cholesterol, $H D L$ high-density lipoprotein cholesterol, $T G$ triglyceride, $d C V$ change in the coefficient of variation, $d L$ R $R H I$ change in the natural logarithmic scaled reactive hyperemia index.

through increased oxidative stress and the appearance of endothelial cell adhesion factors following enhancement of protein kinase $\mathrm{C}$ and nuclear factor $\mathrm{K}$-light-chainenhancer of activated B activity, consequence to postprandial hyperglycemia and/or postprandial lipemia [19]. However, the state of high oxidative stress in various diseases, including chronic glucose and lipid metabolism disorders, hypertension, and chronic kidney disease, plays an important role in increasing the level of asymmetrical dimethylarginine [20], which is considered the main compound responsible for endothelial damage. In this study, similar to the report of Koska et al. [21], vascular endothelial dysfunction elicited by the test meal improved by single-dose exenatide. Because vascular endothelial dysfunction is a manifestation of early-stage atherosclerosis [2], we suggest that the single dose of exenatide used in this study successfully inhibited postprandial endothelial dysfunction.

It has been reported that GLP-1 receptors are expressed in vascular endothelial cells [22] and it has been reported to directly increase NO production and inhibit the expressions of endothelial cell adhesion factors [23]. GLP-1 increases NO production to improve the vasodilatory response [8]. In addition, GLP-1 is reported to inhibit overexpression of hyperglycemiainduced vascular cell adhesion molecule-1 in vascular endothelial cells [9]. In actual clinical settings, DPP4 inhibitor sitagliptin has been reported to increase GLP-1 and inhibit the expressions of endothelial cell adhesion factors such as intercellular adhesion molecule-1 (ICAM-1) and E-selectin [24], indicating GLP-1 has direct and short-term vasodilatory and anti-inflammatory effects that result in improvement of vascular endothelial function. These effects could, at least in part, explain the improvement in vascular endothelial function observed after in the present study after a single dose of exenatide.

In this study, exenatide administered before the meal loading test inhibited the postprandial increase in triglycerides. Previous studies also showed that a single dose of GLP-1 inhibits the postprandial rise in triglycerides and free fatty acids in healthy persons [25] and inhibits the postprandial rise in triglycerides and apolipoprotein B48 in patients with T2DM [26]. GLP-1 is

Table 4 Results of linear multivariate analysis with $\mathrm{dL}$ RHI as the dependent variable

\begin{tabular}{|c|c|c|c|c|c|c|}
\hline \multirow[t]{2}{*}{ Variables } & \multicolumn{2}{|c|}{ Unstandardized coefficients } & \multirow[t]{2}{*}{ Standardized coefficients $\beta$} & \multirow[t]{2}{*}{$\mathbf{t}$} & \multirow{2}{*}{$\begin{array}{l}P \\
\text { value }\end{array}$} & \multirow[t]{2}{*}{$95 \% \mathrm{Cl}$} \\
\hline & B & SE & & & & \\
\hline Intercept & -0.257 & 0.150 & & -1.721 & 0.111 & $-0.584,0.069$ \\
\hline $\mathrm{dCV}_{\mathrm{TG}}$ & -0.502 & 1.729 & -0.642 & -2.901 & 0.013 & $-0.878,-1.249$ \\
\hline $\mathrm{dAUC}$ glucose & - & - & -0.203 & -0.847 & 0.415 & - \\
\hline Adjusted multiple $\mathrm{R}^{2}$ & 0.412 & & & & & \\
\hline
\end{tabular}

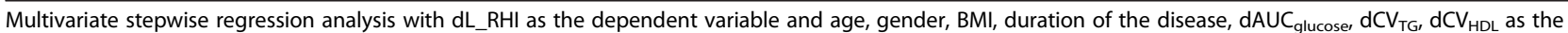
independent variables.

Abbreviations: $d L \_R H I$ change in the natural logarithmic scaled reactive hyperemia index, $d A U C$ change in the area under the curve, $d C V$ change in the coefficient of variation, $H D L$ high-density lipoprotein cholesterol, TG triglyceride, SE Standard error, CVD cardiovascular disease, $95 \%$ CI $95 \%$ confidence interval. 
also reported to suppress chylomicron synthesis by inhibiting apolipoprotein B48 production and triglycerides absorption through direct action on the gastrointestinal tract [7], and inhibits postprandial increase in triglycerides by reducing the gastric emptying rate [27]. It is presumed that the same mechanisms are involved in the improvement of postprandial lipid abnormalities observed in the present study.

Recent large-scale clinical studies have shown that postprandial hypertriglyceridemia increases the risk of cardiovascular events independent of other risk factors of diabetes mellitus, hypertension, and lipid metabolism during fasting $[28,29]$. On the other hand, it has been reported that postprandial deterioration of vascular endothelial function is associated with postprandial hyperglycemia and hypertriglyceridemia [30]. Improvement in vascular endothelial function after single-dose administration of incretin analog alogliptin [31] or exenatide [21] has also been reported to be related to improvement in postprandial lipid abnormalities. In the present study, postprandial hypertriglyceridemia correlated with postprandial decrease in vascular endothelial function, and improvement in postprandial vascular endothelial function after exenatide correlated with improvement in postprandial hypertriglyceridemia. One possible mechanism for this improvement is inhibition of oxidative stress and reduced expression of endothelial cell adhesion factor through improvement in postprandial lipid abnormalities, leading to improvement in vascular endothelial dysfunction. Such improvement seems to be due to the indirect and short-term effects of exenatide.

This study had certain limitations. First, it was an open-label study covering a small sample size with possible selection bias. It has been reported that GLP-1 formulations did not improve vascular endothelial function in T2DM patients with severe obesity [32] or vascular endothelial function in fasting [33]. Therefore, the finding needs to be validated in a larger sample size in the future. Second, the direct effect of GLP-1 on inflammatory cytokines, adhesion factors, oxidative stress factors, among others, and their effects on vascular endothelial function, was not evaluated in this study. Since GLP-1 formulations are known to suppress oxidative stress and inflammation and thus suppress vascular endothelial dysfunction [34]. Our results showed that improvement in postprandial hypertriglyceridemia was responsible for $41 \%$ improvement in postprandial vascular endothelial function, while the remaining 59\% was probably related to the direct effect of GLP-1 on vascular endothelial function. Further studies are required to examine the direct effects of GLP-1 on vascular endothelial function that are independent of improvement in glucose and lipid metabolism.

\section{Conclusions}

Administration of a single dose of exenatide before the meal loading test inhibited postprandial vascular endothelial dysfunction in patients with T2DM, suggesting multitude of activities in the anti-atherosclerotic effects of exenatide.

\section{Abbreviations}

GLP-1: Glucagon-like peptide-1; T2DM: Type 2 diabetes mellitus; RHI: Reactive hyperemia index; L_RHI: Natural logarithmically-scaled RHI; TG: Triglycerides; CV: Coefficient of variation; NO: Nitric oxide; PAT: Peripheral arterial tonometry; IRI: Immunoreactive insulin; HDL-C: High-density lipoprotein cholesterol; LDL-C: Low-density lipoprotein cholesterol; AUC: Area under the curve; HbA1c: Hemoglobin Alc; BMI: Body mass index; ICAM-1: Intercellular adhesion molecule-1.

\section{Competing interests}

The authors declare that they have no competing interests.

\section{Authors' contributions}

All authors listed on the manuscript participated in the design of the study and in writing the manuscript. KT performed the statistical analysis.

All authors read and approved the final manuscript.

\section{Acknowledgments}

The authors thank Ms. N. Sakaguchi for the excellent technical assistance.

Received: 9 December 2014 Accepted: 29 January 2015

Published online: 18 February 2015

\section{References}

1. Emerging Risk Factors Collaboration. Diabetes mellitus, fasting blood glucose concentration, and risk of vascular disease: a collaborative meta-analysis of 102 prospective studies. Lancet. 2010;375:2215-22.

2. Xu J, Zou MH. Molecular insights and therapeutic targets for diabetic endothelial dysfunction. Circulation. 2009;120:1266-86.

3. Verma S, Anderson TJ. Fundamentals of endothelial function for the clinical cardiologist. Circulation. 2002;105:546-9.

4. Ceriello A, Assaloni R, Da Ros R, Maier A, Piconi L, Quagliaro L, et al. Effect of atorvastatin and irbesartan, alone and in combination, on postprandial endothelial dysfunction, oxidative stress, and inflammation in type 2 diabetic patients. Circulation. 2005;111:2518-24.

5. Ceriello A. Postprandial hyperglycemia and diabetes complications: is it time to treat? Diabetes. 2005;54:1-7.

6. Enkhmaa B, Ozturk Z, Anuurad E, Berglund L. Postprandial lipoproteins and cardiovascular disease risk in diabetes mellitus. Curr Diab Rep. 2010;10:61-9.

7. Hsieh J, Longuet C, Baker CL, Qin B, Federico LM, Drucker DJ, et al. The glucagon-like peptide 1 receptor is essential for postprandial lipoprotein synthesis and secretion in hamsters and mice. Diabetologia. 2010;53:552-61.

8. Richter G, Feddersen O, Wagner U, Barth P, Göke R, Göke B. GLP-1 stimulates secretion of macromolecules from airways and relaxes pulmonary artery. Am J Physiol. 1993;265:374-81.

9. Liu H, Dear AE, Knudsen LB, Simpson RW. A long-acting glucagon-like peptide-1 analogue attenuates induction of plasminogen activator inhibitor type-1 and vascular adhesion molecules. J Endocrinol. 2009;201:59-66.

10. Nakamura K, Oe H, Shimada K, Fukuda S, Watanabe K, Takagi T, et al. DPP-4 inhibitor and alpha-glucosidase inhibitor equally improve endothelial function in patients with type 2 diabetes: EDGE study. Cardiovasc Diabetol 2014;13:110.

11. Ishikawa S, Shimano M, Watarai M, Koyasu M, Uchikawa T, Ishii H, et al. Impact of sitagliptin on carotid intima-media thickness in patients with coronary artery disease and impaired glucose tolerance or mild diabetes mellitus. Am J Cardiol. 2014;114:384-8

12. Nyström T, Gutniak MK, Zhang Q, Zhang F, Holst JJ, Ahrén B, et al. Effects of glucagon-like peptide-1 on endothelial function in type 2 diabetes patients with stable coronary artery disease. Am J Physiol Endocrinol Metab. 2004;287:1209-15

13. Yoshino G, Tominaga M, Hirano T, Shiba T, Kashiwagi A, Tanaka A, et al. The test meal $A$ : a pilot model for the international standard of test meal for an 
assessment of both postprandial hyperglycemia and hyperlipidemia. J Jpn Diabetes Soc. 2006;49:361-71.

14. Bonetti PO, Pumper GM, Higano ST, Holmes Jr DR, Kuvin JT, Lerman A. Noninvasive identification of patients with early coronary atherosclerosis by assessment of digital reactive hyperemia. J Am Coll Cardiol. 2004;44:2137-41.

15. The Committee of Japan Diabetes Society on the diagnostic criteria of diabetes mellitus. Report of the Committee on the classification and diagnostic criteria of diabetes mellitus. J Diabetes Invest. 2010;1:212-28.

16. Best $\mathrm{JH}$, Hoogwerf BJ, Herman WH, Pelletier EM, Smith DB, Wenten $\mathrm{M}$, et al. Risk of cardiovascular disease events in patients with type 2 diabetes prescribed the glucagon-like peptide 1 (GLP-1) receptor agonist exenatide twice daily or other glucose-lowering therapies: a retrospective analysis of the LifeLink database. Diabetes Care. 2011;34:90-5.

17. Rizzo M, Chandalia M, Patti AM, Di Bartolo V, Rizvi AA, Montalto G, et al. Liraglutide decreases carotid intima-media thickness in patients with type 2 diabetes: 8-month prospective pilot study. Cardiovasc Diabetol. 2014;13:49.

18. Shimabukuro M, Higa N, Chinen I, Yamakawa K, Takasu N. Effects of a single administration of acarbose on postprandial glucose excursion and endothelial dysfunction in type 2 diabetic patients: a randomized crossover study. J Clin Endocrinol Metab. 2006;91:837-42.

19. Ceriello A, Motz E. Is oxidative stress the pathogenic mechanism underlying insulin resistance, diabetes, and cardiovascular disease? The common soil hypothesis revisited. Arterioscler Thromb Vasc Biol. 2004;24:816-23.

20. Ueda S, Yamagishi S, Kaida Y, Okuda S. Asymmetric dimethylarginine may be a missing link between cardiovascular disease and chronic kidney disease. Nephrology (Carlton). 2007;12:582-90.

21. Koska J, Schwartz EA, Mullin MP, Schwenke DC, Reaven PD. Improvement of postprandial endothelial function after a single dose of exenatide in individuals with impaired glucose tolerance and recent-onset type 2 diabetes. Diabetes Care. 2010;33:1028-30.

22. Ban K, Noyan-Ashraf MH, Hoefer J, Bolz SS, Drucker DJ, Husain M. Cardioprotective and vasodilatory actions of glucagon-like peptide 1 receptor are mediated through both glucagon-like peptide 1 receptordependent and -independent pathways. Circulation. 2008;117:2340-50.

23. Oyama J, Higashi Y, Node K. Do incretins improve endothelial function? Cardiovasc Diabetol. 2014;13:21.

24. Tremblay AJ, Lamarche B, Deacon CF, Weisnagel SJ, Couture P. Effects of sitagliptin therapy on markers of low-grade inflammation and cell adhesion molecules in patients with type 2 diabetes. Metabolism. 2014;63:1141-8.

25. Meier JJ, Gethmann A, Götze O, Gallwitz B, Holst JJ, Schmidt WE, et al. Glucagon-like peptide 1 abolishes the postprandial rise in triglyceride concentrations and lowers levels of non-esterified fatty acids in humans. Diabetologia. 2006;49:452-8.

26. Schwartz EA, Koska J, Mullin MP, Syoufi I, Schwenke DC, Reaven PD. Exenatide suppresses postprandial elevations in lipids and lipoproteins in individuals with impaired glucose tolerance and recent onset type 2 diabetes mellitus. Atherosclerosis. 2010;212:217-22.

27. Willms B, Werner J, Holst JJ, Orskov C, Creutzfeldt W, Nauck MA. Gastric emptying, glucose responses, and insulin secretion after a liquid test meal: effects of exogenous glucagon-like peptide-1 (GLP-1)-(7-36) amide in type 2 (noninsulin-dependent) diabetic patients. J Clin Endocrinol Metab. 1996:81:327-32.

28. Bansal S, Buring JE, Rifai N, Mora S, Sacks FM, Ridker PM. Fasting compared with nonfasting triglycerides and risk of cardiovascular events in women. JAMA. 2007;298:309-16.

29. Eberly LE, Stamler J, Neaton JD. Relation of triglyceride levels, fasting and nonfasting, to fatal and nonfatal coronary heart disease. Arch Intern Med. 2003;163:1077-83.

30. Ceriello A, Taboga C, Tonutti L, Quagliaro L, Piconi L, Bais B, et al. Evidence for an independent and cumulative effect of postprandial hypertriglyceridemia and hyperglycemia on endothelial dysfunction and oxidative stress generation: effects of short- and long-term simvastatin treatment. Circulation. 2002;106:1211-8.

31. Noda Y, Miyoshi T, Oe H, Ohno Y, Nakamura K, Toh N, et al. Alogliptin ameliorates postprandial lipemia and postprandial endothelial dysfunction in non-diabetic subjects: a preliminary report. Cardiovasc Diabetol. 2013;12:8.

32. Hopkins ND, Cuthbertson DJ, Kemp GJ, Pugh C, Green DJ, Cable NT, et al. Effects of 6 months glucagon-like peptide-1 receptor agonist treatment on endothelial function in type 2 diabetes mellitus patients. Diabetes Obes Metab. 2013;15:770-3.
33. Nandy D, Johnson C, Basu R, Joyner M, Brett J, Svendsen CB, et al. The effect of liraglutide on endothelial function in patients with type 2 diabetes. Diab Vasc Dis Res. 2014;11:419-30.

34. Ceriello A, Novials A, Ortega E, Canivell S, Pujadas G, La Sala L, et al. Vitamin C further improves the protective effect of GLP-1 on the ischemiareperfusion-like effect induced by hyperglycemia post-hypoglycemia in type 1 diabetes. Cardiovasc Diabetol. 2013;12:97.

\section{Submit your next manuscript to BioMed Central and take full advantage of:}

- Convenient online submission

- Thorough peer review

- No space constraints or color figure charges

- Immediate publication on acceptance

- Inclusion in PubMed, CAS, Scopus and Google Scholar

- Research which is freely available for redistribution 